\title{
Measuring Health in Patients With Fibromyalgia: Content Comparison of Questionnaires Based on the International Classification of Functioning, Disability and Health
}

\author{
BIRGIT PRODINGER, ${ }^{1}$ ALARCOS CIEZA, ${ }^{2}$ DAVID A. WILLIAMS,${ }^{3}$ PHILIP MEASE, ${ }^{4}$ \\ ANNELIES BOONEN,${ }^{5}$ KATHARINA KERSCHAN-SCHINDL, ${ }^{1}$ VERONIKA FIALKA-MOSER, ${ }^{1}$ \\ JOSEF SMOLEN, ${ }^{1}$ GEROLD STUCKI, ${ }^{6}$ KLAUS MACHOLD, ${ }^{1}$ AND TANJA STAMM ${ }^{1}$
}

\begin{abstract}
Objective. To analyze the content of outcome measures commonly used to assess health in patients with fibromyalgia (FM) by linking the items of the instruments with the International Classification of Functioning, Disability and Health (ICF) in order to evaluate the adequacy of currently used measures.

Methods. Questionnaires used in FM were identified in a structured literature search. All concepts included in the items of the questionnaires were linked to ICF categories, according to previously published linking rules, by 2 independent health professionals. The percentages of linked ICF categories addressing the different ICF components were calculated. Results. Generic and symptom-specific instruments were included. From the 296 items contained in all 16 instruments, 447 concepts were extracted and then linked to 52 ICF categories of the component body functions, 1 category of the component body structure, 40 categories of the component activities and participation, and 9 categories of the component environmental factors. More than half of the concepts identified were linked to body function, fewer were linked to activities and participation, and only concepts of 4 instruments were linked to the ICF component environmental factors. Conclusion. Many concepts were linked to the categories in the ICF component body functions. While linking to the broad category, purportedly similar instruments often covered widely varying areas of function at more fine-grained levels of detail. Some categories, such as environmental factors, were barely covered by any of the instruments and might constitute an important aspect of health deserving better coverage and future development.
\end{abstract}

\section{INTRODUCTION}

Fibromyalgia (FM) is a chronic pain condition characterized by widespread pain and tenderness. The American College of Rheumatology established criteria for the classification of FM that require the following: a history of widespread pain for at least 3 months and tenderness in at least 11 of 18 defined tender points (1). Using this definition, $2-4 \%$ of the population in industrialized countries satisfy the criteria for having FM (2). In clinical practice, however, patients tend to report a more complex set of

${ }^{1}$ Birgit Prodinger, OTR, Katharina Kerschan-Schindl, MD, Veronika Fialka-Moser, MD, Josef Smolen, MD, Klaus Machold, MD, Tanja Stamm, PhD, MSc, MBA: Medical University of Vienna, Vienna, Austria; ${ }^{2}$ Alarcos Cieza, PhD, MPH: International Classification of Functioning, Disability and Health Research Branch, DIMDI, Munich, Germany; ${ }^{3}$ David A. Williams, PhD: University of Michigan, Ann Arbor; ${ }^{4}$ Philip Mease, MD: Seattle Rheumatology Associates, Seattle, Washington; ${ }^{5}$ Annelies Boonen, MD, PhD: University Hospital Maastricht, Maastricht, The Netherlands; concerns, including fatigue, sleep dysfunction, stiffness, depression, anxiety, poor physical functioning, and cognitive disturbance in addition to pain/tenderness $(3,4)$.

The underlying pathology of FM remains poorly understood, but dysfunction in central neurobiologic structures is suspected $(5,6)$. Actual symptom expression in FM tends to vary on an individual basis, suggesting heterogeneity in the underlying mechanisms of FM and the possibility of subgroups of patients with FM $(3,7)$.

FM is best treated using dually focused interventions: pharmacologic agents to address issues of central pain and

${ }^{6}$ Gerold Stucki, MD, MS: International Classification of Functioning, Disability and Health Research Branch, DIMDI, and Ludwig-Maximilians-University, Munich, Germany.

Address correspondence to Birgit Prodinger, OTR, Vienna University, Department of Internal Medicine III, Division of Rheumatology, Währinger Gürtel 18-20, A-1090 Vienna, Austria. E-mail: birgit.prodinger@meduniwien.ac.at.

Submitted for publication July 24, 2007; accepted in revised form October 22, 2007. 
nonpharmacologic approaches, e.g., aerobic exercise and/or cognitive-behavioral therapy, to address some of the functional consequences of pain, for instance, deconditioning, poor function, and deteriorated mood (8). Significant effort is being applied to the development of new interventions (both pharmacologic and nonpharmacologic) specifically targeting FM. To determine the efficacy of these therapies, a variety of outcome measures have been used to assess improvement in patients with FM, but there has not been uniform agreement as to which domains or which assessment tools should be utilized. Two organizations have provided some guidance in this regard. The first, the Initiative on Methods, Measurement, and Pain Assessment in Clinical Trials (IMMPACT), utilized the opinions of an expert consensus panel to determine what should be assessed in any clinical trial designed to assess the efficacy and effectiveness of treatments for chronic pain. This group suggested that the following outcome domains be considered: pain, physical functioning, emotional functioning, patient global ratings of satisfaction, negative health states, adverse events, and patient adherence to the treatment (9). The second group, the Outcome Measures in Rheumatology Clinical Trials (OMERACT) Fibromyalgia Syndrome working group, sought consensus from both patients and clinicians regarding the relevant outcome domains to specifically assess FM. Many of the same domains as defined by IMMPACT were identified for pain, but in addition, problems with sleep, cognition, tenderness, and stiffness were included as concerns more specific to FM (10).

With so many domains and instruments focused on health and functioning, clinicians and researchers can become mired in confusion. Further complicating the picture, assessment instruments claiming to assess the same domain often contain items that assess multiple domains that can differ depending upon the instrument. These differences between supposedly similar assessment tools are in part due to initial vagaries in the domain definition during instrument development.

The International Classification of Functioning, Disability and Health (ICF) (11) classifies health and health-related status and offers a comprehensive understanding of functioning in relation to a disease. In the ICF, functioning is described as the complex interplay of the health components body functions, body structures, activities and participation, and contextual factors, such as environmental and personal factors. Activity is defined in the ICF as the execution of a task or action by an individual, whereas participation is the person's involvement in a daily life situation. Participation may therefore be considered important from the perspective of patients because it refers to whether restrictions are experienced in daily life situations.

To date, no studies have evaluated whether the instruments commonly used to assess outcomes in FM align with the categories of function as defined by the ICF. The outcomes of such a study could both enlighten current instrument selection for assessing function and health in patients with FM and inform the development of new tools (3). Therefore, the goal of this study was to aggregate all items of all questionnaires commonly used to assess FM and then link the content of those items to specific ICF codes. The intent of this process was to inform clinicians and researchers of the specific areas of health (based on content comparison) that are assessed when each questionnaire is administered and to help identify gaps in our current assessment batteries used to assess the multiple relevant domains of FM.

\section{MATERIALS AND METHODS}

Search strategy. A structured literature search was performed in spring 2007. The following databases were searched using the keywords "instrument," "measure," "assessment," "questionnaire," "functional assessment," "function," and "fibromyalgia": CINAHL (1982-2007), PsychINFO (1988-2007), EMBase (1988-2007), and Medline (1950-2007). Eligibility of the questionnaires was checked in 3 steps. In the first step, descriptive, evaluative, and psychometric studies were selected. Case reports, economic evaluations, primary prevention studies, and reviews were excluded. In the second step, studies and articles that reported the use of functional status questionnaires were selected. In the third step, the following criteria and instruments were applied: questionnaires that 1) assessed functioning and/or health, 2) were specifically developed for FM or were used to assess symptoms associated with FM in studies addressing FM (e.g., depression, fatigue), 3) were published in a peer-reviewed journal, and 4) exist in an English version.

The ICF categorization scheme. In the ICF classification, the letters b, s, d, and e represent functional components (i.e., body functions [b], body structures [s], activities and participation [d], and environmental factors [e]). The components of the ICF are followed by a numeric code starting with the chapter number (e.g., Chapter 6: Domestic Life; 1 digit), followed by the second level (2 digits) and the third and fourth levels (1 digit each). For example, coding "diminished sleep" might use the following coding scheme: the letter (component) would be body functions (b) and would be followed by the digit 1 representing Chapter 1 (Mental Functions) and would thus result in the first-level code b1 mental functions. The second-level code would be b134 sleep functions and the third-level code, b1340 amount of sleep. The fourth level is not available in this case. At the end of each chapter, there are other specified categories (uniquely identified by the final code 8) and unspecified categories (uniquely identified by the final code 9).

Linking to the ICF codes. Linking rules have been developed to link functioning instruments to the ICF in a specific and precise manner $(12,13)$. Based on these linking rules, each item of an instrument should be linked to the ICF category that most precisely represents the item's content. An item of a questionnaire can include more than 1 concept, thus the first step of the analysis was to identify the concepts in each item. A concept was defined as 1 separate meaningful entity, such as a body structure, a 
Table 1. Linking of the items of the Fibromyalgia Impact Questionnaire (FIQ) to the ICF*

\begin{tabular}{|c|c|c|}
\hline FIQ item & Concept & ICF category \\
\hline 1. Were you able to do shopping? & To shop & d6200 Shopping \\
\hline $\begin{array}{l}\text { 2. Were you able to do laundry } \\
\text { with a washer and dryer? }\end{array}$ & To do laundry & d6403 Using household appliances \\
\hline 3. Were you able to prepare meals? & To prepare meal & d630 Preparing meals \\
\hline $\begin{array}{l}\text { 4. Were you able to wash dishes/ } \\
\text { cooking utensils by hand? }\end{array}$ & To wash the dishes & $\begin{array}{l}\text { d6401 Cleaning cooking area and } \\
\text { utensils }\end{array}$ \\
\hline 5. Were you able to vacuum a rug? & To vacuum a rug & d6403 Using household appliances \\
\hline 6. Were you able to make beds? & To make beds & d640 Doing housework \\
\hline $\begin{array}{l}\text { 7. Were you able to walk several } \\
\text { blocks? }\end{array}$ & To walk & d4501 Walking long distances \\
\hline $\begin{array}{l}\text { 8. Were you able to visit friends or } \\
\text { relatives? }\end{array}$ & To visit friends/relatives & d9205 Socializing \\
\hline 9. Were you able to do yard work? & To do yard work & $\begin{array}{l}\text { d6505 Taking care of plants, } \\
\text { indoors and outdoors }\end{array}$ \\
\hline 10. Were you able to drive a car? & To drive a car & d4751 Driving motorized vehicles \\
\hline 11. Were you able to climb stairs? & To climb stairs & d4551 Climbing \\
\hline $\begin{array}{l}\text { 12. Of the } 7 \text { days in the past week, } \\
\text { how many days did you feel } \\
\text { good? }\end{array}$ & To feel good & pf \\
\hline \multirow{3}{*}{$\begin{array}{l}\text { 13. How many days last week did } \\
\text { you miss work, including } \\
\text { housework, because of } \\
\text { fibromyalgia? }\end{array}$} & To miss work & d850 Remunerative employment \\
\hline & To do housework & d640 Doing housework \\
\hline & Fibromyalgia & hc \\
\hline \multirow{4}{*}{$\begin{array}{l}\text { 14. When you worked, how much } \\
\text { did pain or other symptoms of } \\
\text { your fibromyalgia interfere with } \\
\text { your ability to do your work, } \\
\text { including housework? }\end{array}$} & Pain & b280 Sensation of pain \\
\hline & $\begin{array}{l}\text { Other symptoms of } \\
\text { fibromyalgia }\end{array}$ & hc \\
\hline & To work & d850 Remunerative employment \\
\hline & To do housework & d640 Doing housework \\
\hline 15. How bad has your pain been? & Pain & b280 Sensation of pain \\
\hline 16. How tired have you been? & To be tired & b1300 Energy level \\
\hline $\begin{array}{l}\text { 17. How have you felt when you get } \\
\text { up in the morning? }\end{array}$ & $\begin{array}{l}\text { Feeling when getting up in } \\
\text { the morning }\end{array}$ & b1343 Quality of sleep \\
\hline $\begin{array}{l}\text { 18. How bad has your stiffness } \\
\text { been? }\end{array}$ & Stiffness & b7800 Sensation of muscle stiffness \\
\hline \multirow{2}{*}{$\begin{array}{l}\text { 19. How nervous or anxious have } \\
\text { you felt? }\end{array}$} & To be nervous & b1470 Psychomotor control \\
\hline & To be anxious & b1522 Range of emotion \\
\hline $\begin{array}{l}\text { 20. How depressed or blue have } \\
\text { you felt? }\end{array}$ & To feel depressed or blue & b152 Emotional functions \\
\hline
\end{tabular}

body function, an activity, or a contextual factor. Table 1 shows the linking of the items of the Fibromyalgia Impact Questionnaire (FIQ) to the appropriate categories of the ICF, e.g., item 14 of the FIQ: "When you worked, how much did pain or other symptoms of your fibromyalgia interfere with your ability to do your work, including housework?" In this item, the following 4 concepts were identified: 1) "pain," 2) "other symptoms of your fibromyalgia," 3) “work," and 4) "housework." The 4 concepts were linked to the following ICF categories: b280 sensation of pain, d640 doing housework, d850 remunerative employment, and hc (health condition). For the purpose of this study, a meaningful concept that referred to a diagnosis or a health condition, such as "symptoms of your fibromyalgia," was assigned to hc.

If the content of a concept was more general than the corresponding ICF category, the code of the higher level was linked. An example is the concept "I have to limit my social activity" from the Functional Assessment of
Chronic Illness Therapy-Fatigue Scale (FACIT-FS), which was linked to Chapter 9: Community, Social and Civic Life because "my social activity" is more general than the available second-level categories in this chapter. A concept that was considered as not being contained in the ICF classification was assigned as not covered, for instance, the concept "attempts at suicides" of the Hamilton Rating Scale for Depression (HRSD). Furthermore, if the information about a concept was not sufficient to make a decision about the most appropriate ICF category, the concept was linked to not definable, such as "I am forced to spend time in bed," a concept of the fatigue-assessment questionnaire FACIT-F.

The linking process was carried out by 2 health professionals according to the description or definition of the item of the instrument in the literature. The number of concepts identified in each questionnaire and the ICF categories linked were reported both in total and separated by component. 


\section{Table 2. Questionnaires included in the analysis}

\begin{tabular}{l}
\hline \multicolumn{1}{c|}{ Instrument (reference) } \\
\hline Fibromyalgia specific \\
Fibromyalgia Impact Questionnaire (FIQ) (18) \\
Pain \\
McGill Pain Questionnaire (MPQ) (19) \\
Short Form McGill Pain Questionnaire (SF-MPQ) (20) \\
Brief Pain Inventory (BPI) (21) \\
Leeds Assessment of Neuropathic Symptoms and \\
Signs Pain Scale (LANSS) (22) \\
Fatigue \\
Functional Assessment of Chronic Illness Therapy \\
(FACIT-FS) (30) \\
Functional Assessment of Chronic Illness Therapy- \\
Fatigue (FACIT-F) (30) \\
Fatigue Severity Scale (FSS) (31) \\
Multidimensional Fatigue Inventory (MFI) (32) \\
Multidimensional Assessment of Fatigue (MAF) (33,40) \\
Sleep \\
Sleep scale from Medical Outcomes Study (MOS) (26) \\
General health \\
Short Form 36 Health Survey (SF-36) (36,37) \\
Sexuality \\
Arizona Sexual Experiences Scale (ASEX) (34) \\
Depression \\
Beck Depression Inventory (BDI) (38) \\
Hospital Anxiety and Depression Scale (HADS) (10) \\
Hamilton Rating Scale for Depression (HRSD) (38) \\
\hline
\end{tabular}

Rater interreliability. Consensus between 2 health professionals (Edda Amann and Barbara Kollerits) was used to determine which concepts were identified in all items of the questionnaires and which ICF category should be linked to each concept. In the case of disagreement between the 2 health professionals, a third person trained in the linking rules was consulted. In a discussion led by the third person (AC), the 2 health professionals that linked the concept stated pros and cons for the identification of a concept and for linking this concept to a specific ICF category. Based on these statements, the third person made an informed decision.

The degree of agreement between the 2 health professionals regarding the identified and linked concepts was calculated by means of the kappa statistic (14). Kappa values generally range from 0 to 1 , where 1 indicates perfect agreement and 0 indicates no additional agreement beyond what is expected by chance alone. A kappa coefficient $>0.61$ was regarded as good or acceptable for this study (15). The statistical analysis was performed with SPSS 12.0.1 (SPSS, Chicago, IL).

\section{RESULTS}

Literature search. In step 1, the literature search produced 284 hits in CINAHL, 52 in PsychINFO, 547 in EMBase, and 661 in Medline. In the second step, the selection criteria for the articles were applied and 24 articles and 5 abstracts were reviewed in detail. In the third step, 16 questionnaires were identified according to the selection criteria and included in the analysis and are

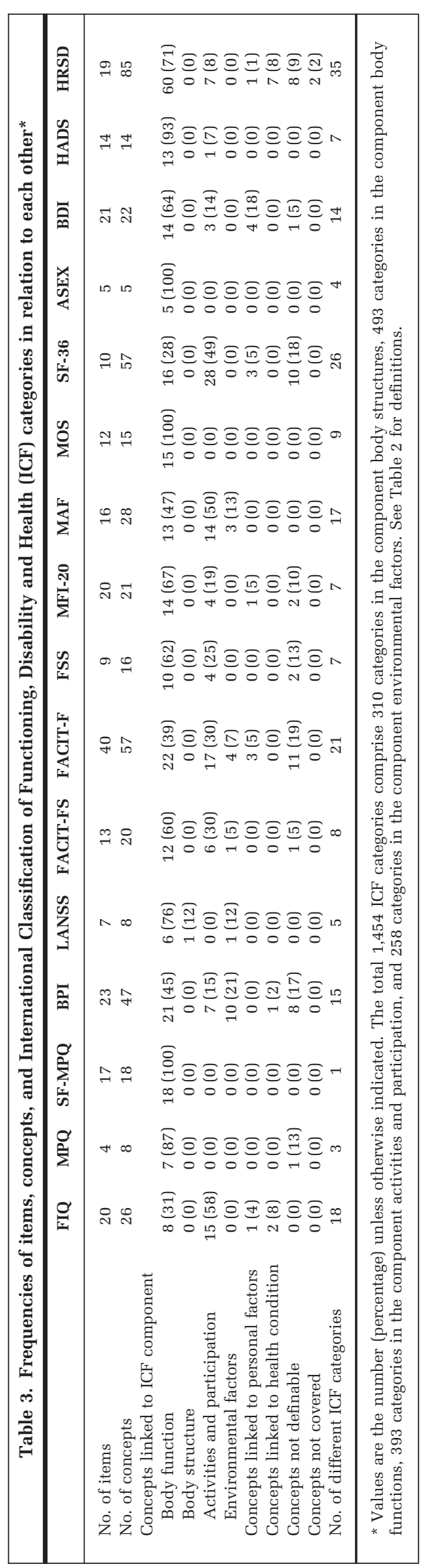


Table 4. International Classification of Functioning, Disability and Health (ICF) categories covered by each instrument*

\begin{tabular}{|c|c|c|c|c|c|c|c|c|c|c|c|c|c|c|c|c|}
\hline ICF category & FIQ & MPQ & $\begin{array}{l}\text { SF- } \\
\text { MPQ }\end{array}$ & BPI & LANSS & $\underset{\text { FS }}{\text { FACIT- }}$ & $\underset{F}{\text { FACIT- }}$ & FSS & MFI- & MAF & MOS & $\begin{array}{l}\text { SF- } \\
36\end{array}$ & ASEX & BDI & HADS & HRSD \\
\hline \multicolumn{17}{|l|}{ Body functions } \\
\hline b1100 State of consciousness & & & & & & & & & & & & & & & & 1 \\
\hline b1261 Agreeableness & & & & & & & & & & & & & & & & 1 \\
\hline b1263 Psychic stability & & & & & & & & & & & & & & 1 & & 1 \\
\hline b1265 Optimism & & & & & & & & & & & & & & 1 & & 3 \\
\hline b1266 Confidence & & & & & & & & & & & & & & 3 & & \\
\hline b130 Energy and drive function & & & & & & & & & & 6 & & 1 & & & & \\
\hline b1300 Energy level & 1 & & & & & 11 & 11 & 8 & 6 & & 2 & 3 & & 1 & 1 & 2 \\
\hline b1301 Motivation & & & & & & & & 1 & 1 & & & & & & & \\
\hline b1302 Appetite & & & & & & & & & & & & & & 1 & & 1 \\
\hline b134 Sleep functions & & & & 1 & & & & & & & 1 & & & & & \\
\hline b1340 Amount of sleep & & & & & & & & & & & 2 & & & & & \\
\hline b1341 Onset of sleep & & & & & & & & & & & 3 & & & & & 2 \\
\hline b1342 Maintenance of sleep & & & & & & & & & & & 2 & & & & & 3 \\
\hline b1343 Quality of sleep & 1 & & & & & & 1 & & & & 2 & & & 1 & & \\
\hline b140 Attention functions & & & & & & & & & 3 & & & & & & & \\
\hline b1400 Sustaining attention & & & & & & & & & 1 & & & & & & & \\
\hline b1470 Psychomotor control & 1 & & & & & & & & & & & 1 & & & 1 & 5 \\
\hline b152 Emotional functions & 1 & & & 1 & & 1 & 8 & & 1 & 1 & & 8 & & 2 & 7 & 5 \\
\hline b1522 Range of emotion & 1 & & & 1 & & & & & & & & 1 & & & 2 & 4 \\
\hline b1600 Pace of thought & & & & & & & & & & & & & & & & 1 \\
\hline b1602 Content of thought & & & & & & & & & & & & & & 1 & 1 & 10 \\
\hline b1603 Control of thought & & & & & & & & & & & & & & & & 1 \\
\hline b1644 Insight & & & & & & & & & & & & & & & & 1 \\
\hline b1800 Experience of self & & & & & & & & & & & & & & & & 2 \\
\hline b1801 Body image & & & & & & & & & & & & & & 1 & 1 & \\
\hline b2702 Sensitivity to pressure & & & & & 1 & & & & & & & & & & & \\
\hline b280 Sensation of pain & 2 & 4 & 18 & 14 & 3 & & 1 & & & & & 2 & & & & \\
\hline b2801 Pain in body part & & & & 2 & & & & & & & & & & & & \\
\hline b28010 Pain in head and neck & & 2 & & 2 & & & & & & & 1 & & & & & 1 \\
\hline \multicolumn{17}{|l|}{ Body functions } \\
\hline $\begin{array}{l}\text { b28012 Pain in stomach or } \\
\text { abdomen }\end{array}$ & & 1 & & & & & & & & & & & & & & \\
\hline b28013 Pain in back & & & & & & & & & & & & & & & & 1 \\
\hline b3302 Speed of speech & & & & & & & & & & & & & & & & 1 \\
\hline b410 Heart functions & & & & & & & & & & & & & & & & 1 \\
\hline b440 Respiration functions & & & & & & & & & & & & & & & & 1 \\
\hline $\begin{array}{l}\text { b450 Additional respiratory } \\
\text { functions }\end{array}$ & & & & & & & & & & & 1 & & & & & \\
\hline b4550 General physical endurance & & & & & & & & & 2 & & & & & & & \\
\hline b4552 Fatiguability & & & & & & & & 1 & & 6 & & & & & & 1 \\
\hline $\begin{array}{l}\text { b460 Sensations associated with } \\
\text { cardiovascular and } \\
\text { respiratory functions }\end{array}$ & & & & & & & & & & & 1 & & & & & 1 \\
\hline b515 Digestive functions & & & & & & & & & & & & & & & & 3 \\
\hline b5252 Frequency of defecation & & & & & & & & & & & & & & & & 1 \\
\hline b5254 Flatulence & & & & & & & & & & & & & & & & 1 \\
\hline $\begin{array}{l}\text { b530 Weight maintenance } \\
\text { functions }\end{array}$ & & & & & & & & & & & & & & 1 & & 1 \\
\hline $\begin{array}{l}\text { b535 Sensations associated with } \\
\text { the digestive system }\end{array}$ & & & & & & & & & & & & & & & & 1 \\
\hline b5350 Sensations of nausea & & & & & & & 1 & & & & & & & & & \\
\hline b620 Urination functions & & & & & & & & & & & & & & & & 1 \\
\hline b640 Sexual functions & & & & & & & & & & & & & 2 & & & 1 \\
\hline $\begin{array}{l}\text { b6400 Functions of sexual arousal } \\
\text { phase }\end{array}$ & & & & & & & & & & & & & 1 & 1 & & \\
\hline $\begin{array}{l}\text { b6402 Functions of orgasmic } \\
\text { phase }\end{array}$ & & & & & & & & & & & & & 1 & & & \\
\hline $\begin{array}{l}\text { b6403 Functions of sexual } \\
\text { resolution phase }\end{array}$ & & & & & & & & & & & & & 1 & & & \\
\hline $\begin{array}{l}\text { b780 Sensations related to } \\
\text { muscles and movement } \\
\text { functions }\end{array}$ & & & & & & & & & & & & & & & & 1 \\
\hline $\begin{array}{l}\text { b7800 Sensation of muscle } \\
\text { stiffness }\end{array}$ & 1 & & & & & & & & & & & & & & & \\
\hline b840 Sensation related to skin & & & & & 2 & & & & & & & & & & & \\
\hline \multicolumn{17}{|l|}{ Body structure } \\
\hline s810 Structure of areas of skin & & & & & 1 & & & & & & & & & & & \\
\hline \multicolumn{17}{|l|}{ Activities and participation } \\
\hline d177 Making decisions & & & & & & & & & & & & & & 1 & & 2 \\
\hline d2200 Carrying out multiple tasks & & & & & & 1 & 1 & & & & & & & & (cont & tinued) \\
\hline
\end{tabular}


Table 4. International Classification of Functioning, Disability and Health (ICF) categories covered by each instrument* (Continued)

\begin{tabular}{|c|c|c|c|c|c|c|c|c|c|c|c|c|c|c|c|c|}
\hline ICF category & FIQ & MPQ & $\begin{array}{l}\text { SF- } \\
\text { MPQ }\end{array}$ & BPI & LANSS & $\underset{\text { FS }}{\text { FACIT- }}$ & $\underset{\text { F }}{\text { FACIT- }}$ & FSS & $\underset{20}{\text { MFI- }}$ & MAF & MOS & $\begin{array}{l}\text { SF- } \\
36\end{array}$ & ASEX & BDI & HADS & HRSD \\
\hline d2201 Completing multiple tasks & & & & & & 1 & 1 & & & & & & & & & \\
\hline d230 Carrying out daily routine & & & & & & 2 & 2 & 1 & 3 & & & 2 & & & & \\
\hline d4102 Kneeling & & & & & & & & & & & & 1 & & & & \\
\hline d4105 Bending & & & & & & & & & & & & 2 & & & & \\
\hline d4154 Maintaining a standing position & & & & 1 & & & & & & & & & & & & \\
\hline d430 Lifting and carrying objects & & & & & & & & & & & & 1 & & & & \\
\hline d4300 Lifting & & & & 1 & & & & & & & & 1 & & & & \\
\hline d4450 Pulling & & & & & & & & & & & & 1 & & & & \\
\hline d450 Walking & & & & 2 & & & & & & 1 & & & & & & \\
\hline d4500 Walking short distances & & & & & & & & & & & & 1 & & & & \\
\hline d4501 Walking long distances & 1 & & & & & & & & & & & 2 & & & & \\
\hline d4551 Climbing & 1 & & & & & & & & & & & 2 & & & & \\
\hline d4552 Running & & & & & & & & & & & & 1 & & & & \\
\hline d4751 Driving motorized vehicles & 1 & & & & & & & & & & & & & & & \\
\hline d510 Washing oneself & & & & & & & & & & 1 & & & & & & \\
\hline d5101 Washing whole body & & & & & & & & & & & & 1 & & & & \\
\hline d540 Dressing & & & & & & & & & & 1 & & 1 & & & & \\
\hline d550 Eating & & & & & & 1 & 1 & & & & & & & & & \\
\hline d620 Acquisition of goods and services & & & & & & & & & & 1 & & & & & & \\
\hline d6200 Shopping & 1 & & & & & & & & & & & & & & & \\
\hline d630 Preparing meals & 1 & & & & & & & & & 1 & & & & & & \\
\hline d640 Doing housework & 3 & & & 1 & & & 2 & & & 1 & & 1 & & & & \\
\hline $\begin{array}{l}\text { d6401 Cleaning cooking area and } \\
\text { utensils }\end{array}$ & 1 & & & & & & & & & & & & & & & \\
\hline d6403 Using household appliances & 2 & & & & & & & & & & & 1 & & & & \\
\hline $\begin{array}{l}\text { d6505 Taking care of plants, indoors } \\
\text { and outdoors }\end{array}$ & 1 & & & & & & & & & & & & & & & \\
\hline $\begin{array}{l}\mathrm{d} 7 \text { Interpersonal interactions and } \\
\text { relationship }\end{array}$ & & & & 1 & & & 1 & & & & & & & 1 & & \\
\hline d750 Informal social relationship & & & & & & & & & & & & 1 & & & & \\
\hline $\begin{array}{l}\text { d7500 Informal relationships with } \\
\text { friends }\end{array}$ & & & & & & & 1 & & & & & 1 & & & & \\
\hline $\begin{array}{l}\text { d7501 Informal relationships with } \\
\text { neighbors }\end{array}$ & & & & & & & & & & & & 1 & & & & \\
\hline d760 Family relationships & & & & & & & 3 & 1 & & & & 1 & & & & \\
\hline d770 Intimate relationships & & & & & & & 1 & & & & & & & & & \\
\hline d7702 Sexual relationships & & & & & & & 1 & & & 1 & & & & & & \\
\hline d850 Remunerative employment & 2 & & & 1 & & & 2 & 1 & & & & 3 & & 1 & & 3 \\
\hline d9 Community, social, and civic life & & & & & & 1 & 1 & 1 & & 1 & & & & & & 1 \\
\hline d920 Recreation and leisure & & & & & & & & & 1 & 1 & & & & & 1 & \\
\hline d9201 Sports & & & & & & & & & & 1 & & 3 & & & & \\
\hline d9204 Hobbies & & & & & & & & & & & & & & & & 1 \\
\hline d9205 Socializing & 1 & & & & & & & & & 1 & & 1 & & & & \\
\hline \multicolumn{17}{|l|}{ Environmental factors } \\
\hline e1101 Drugs & & & & 5 & & & & & & & & & & & & \\
\hline $\begin{array}{l}\text { e1150 General products_for personal } \\
\text { use in daily living }\end{array}$ & & & & & 1 & & & & & & & & & & & \\
\hline $\begin{array}{l}\text { e1151 Assistive products-for personal } \\
\text { use in daily living }\end{array}$ & & & & 2 & & & & & & & & & & & & \\
\hline e3 Supports and relationships & & & & & & 1 & 1 & & & & & & & & & \\
\hline e310 Immediate family & & & & & & & 1 & & & 1 & & & & & & \\
\hline e315 Extended family & & & & & & & & & & & & & & & & \\
\hline e320 Friends & & & & & & & 1 & & & 1 & & & & & & \\
\hline $\begin{array}{l}\text { e410 Individual attitudes of immediate } \\
\text { family members }\end{array}$ & & & & & & & 1 & & & & & & & & & \\
\hline e5800 Health services & & & & 3 & & & & & & & & & & & & \\
\hline Not covered & & & & & & & & & & & & & & & & 2 \\
\hline Personal factor & 1 & & & & & & 3 & & 1 & & & 3 & & 3 & & 1 \\
\hline Personal factor-subjective & & & & & & & & & & & & & & 1 & & \\
\hline Health condition & 2 & & & 1 & & & & & & & & & & & & 7 \\
\hline Not definable & & 1 & & 3 & & & 7 & 2 & & & & & & & & 6 \\
\hline Not definable health condition & & & & 3 & & & 1 & & & & & & & & & 1 \\
\hline Not definable activities and participation & & & & 2 & & 1 & 1 & & 2 & 1 & & 2 & & & & \\
\hline Not definable general health & & & & & & & 1 & & & & & 4 & & 1 & & \\
\hline Not definable quality of life & & & & & & & 1 & & & & & & & & & \\
\hline Not definable physical health & & & & & & & & & & & & 3 & & & & \\
\hline Not definable body function & & & & & & & & & & & & & & & & 1 \\
\hline
\end{tabular}

* This table shows the linking of the concepts contained in the items of the instruments using the ICF categories as a reference and ordered by component. Values are the frequencies with which the ICF categories were found to be addressed in the different instruments. A higher number indicates that several concepts from a specific instrument were linked to the same ICF category. See Table 2 for definitions. 
listed in Table 2. Tools currently used are FM specific and symptom specific. The number of items of each questionnaire is presented in Table 3. The FIQ was the only FMspecific instrument in this literature search. Because psychiatric symptoms may influence pain and dysfunction as well as provide a sense of the impact of pain, fatigue, and other symptoms, assessments of depression were included (10).

Instrument item linkage to ICF codes. The linking of the concepts contained in the items of the instruments using the ICF categories as a reference and ordered by components is shown in Table 4 (a-d). The numbers in the table represent the frequencies with which the ICF categories were addressed in the different instruments. A higher number indicates that several concepts from a specific instrument were linked to the same ICF category. For example, the category d760 family relationship was linked to the following 3 concepts of the FACIT-F: "having troubles to meet the needs of the family," "family well-being," and "satisfaction with family communication about illness."

In 296 items of all instruments, 447 concepts were identified, which were then linked to 52 ICF categories of the component body functions, 1 category of the component body structure, 40 categories of the component activities and participation, 9 categories of the component environmental factors, and 13 concepts to personal factors (Table 4 [a-d]). Ten concepts were considered to be related to health condition and were not linked to any ICF category. Forty-four concepts were not definable, and the following 2 concepts were found to be not covered by the ICF: suicides and attempts at suicides (concept in item 3 of the HRSD).

The frequencies of items and concepts of the instruments and ICF categories in relation to each other are shown in Table 3. The total number of the ICF categories linked to the concepts of the questionnaires shows remarkable differences. While some instruments showed a considerable diversity in their content (such as the Short Form 36 [SF-36], which includes 36 items from which 57 concepts were extracted and linked to 44 ICF categories), other instruments were linked to few or only 1 ICF category (such as the Arizona Sexual Experience Scale [ASEX], which includes 5 items from which 5 concepts were extracted and linked to 5 ICF categories).

The kappa statistic for agreement between the 2 investigators was $0.74(P<0.0001)$. The kappa coefficient exceeded 0.61 and thus was regarded as good.

\section{DISCUSSION}

For clinicians and researchers who wish to select an instrument for measuring a specific end point, it is important to know which domains are covered by which instruments and which areas receive no coverage at all. The findings of this study suggest that many areas of health are covered by the most commonly used measures, and that each instrument differs in the breadth of content that items cover.

One-third of the items of the FIQ, the only FM-specific instrument, were linked to body functions and two-thirds were linked to activities and participation. The remaining concepts were linked to health condition or personal factor, such as the item "How many days last week did you miss work, including housework, because of fibromyalgia?" in which the meaningful concept "because of fibromyalgia" was linked to health condition. This instrument clearly links to health condition itself and is therefore not etiologically neutral (16). Because a lack of a clinical basis by which FM might be identified as a separate entity is evident (17), one might argue whether it is possible to have a special instrument in FM or whether a special instrument is required at all. Although it would be desirable for daily clinical practice to have 1 instrument covering the diversity of symptoms in FM, this might raise psychometric difficulties such as insensitivity associated with the multidimensionality, and differential item functioning associated with sex, as occurred in the FIQ (18).

Regarding the 4 instruments used to assess pain (McGill Pain Questionnaire [MPQ], Short Form MPQ [SF-MPQ], Brief Pain Inventory [BPI], and Leeds Assessment of Neuropathic Symptoms and Signs Pain Scale [LANSS] [19-22]), considerable differences occurred in the ICF components covered. While the SF-MPQ was linked to body functions only, the MPQ and LANSS covered mainly body functions, and the BPI showed more diversity and was linked to body functions, activities and participation, and environmental factors. When assessing pain, the assessor must choose the instrument based upon what knowledge is desired (i.e., whether pain is affecting body function or activities and participation). In the literature, pain is described as both a symptom and a contributor to other symptoms such as fatigue, impairment of concentration, negative mood, degraded sleep, and diminished overall activity (9). Although it is evident that environmental factors have an impact on functioning in daily life from the perspective of patients (23-25), not all of the pain assessment instruments addressed these factors.

The Medical Outcomes Study sleeping scale (26) was only linked to body functions and the majority of concepts were linked to the ICF category b134 sleep functions. Many people with FM report sleep disturbances. Sleep impacts pain, fatigue, and social functioning $(27,28)$; nevertheless, it is not clearly stated whether sleep disturbance is a symptom occurring itself or as a comorbidity. The relationship between sleep and pain was investigated by Affleck et al (29), who stated that the relationship might be bidirectional, meaning that pain might increase disturbance in sleep, and disturbed sleep could intensify pain, or even both. Sleep is rarely included in multidimensional assessment instruments; 2 exceptions are the BPI for assessing pain and the HRSD for depression, which include aspects of sleep. However, it might be recommended to assess sleep and pain in patients with FM.

Less than half of the concepts extracted from the fatiguespecific instruments (FACIT-FS, FACIT-F, Fatigue Severity Scale, Multidimensional Fatigue Inventory, Multidimensional Assessment of Fatigue [MAF] [30-33]) were linked to body functions. Activities and participation was covered by all fatigue instruments, whereas environmental factors only occurred in the FACIT-FS, the FACIT-F, and 
the MAF. Coverage of fatigue in FM was considered by patients to be the second most important domain after pain (10), which is consistent with the relative importance of fatigue in the deterioration of activities and participation in other rheumatic diseases of long duration in general $(24,33)$. As with pain, the relative lack of emphasis on environmental factors in the existing instruments assessing fatigue may indicate a gap that deserves future development.

The ASEX, an instrument that assesses sexual function, was only linked to body functions. The assessment of sexual function was considered important both as a domain of human function and because of the potential for adverse effects of medications on sexual function in patients with FM. Female patients with FM have distinct issues associated with sexual function compared with healthy controls (34). Tikiz et al (35) highlighted that the impact of FM on sexual function can be profound in addition to limiting one's ability to perform other essential life tasks and social roles. Sexual dysfunction may also cause significant personal distress and negatively impacts quality of life. In the ASEX, sexual function is assessed solely in the ICF component body functions. This has to be considered because assessing the dysfunction itself does not allow drawing any conclusions about the subjective meaning or choice of sexual function and thus the individual impact on quality of life.

The SF-36 $(36,37)$ and the 3 depression instruments (Beck Depression Inventory, Hospital Anxiety and Depression Scale, HRSD [38]) were linked to body function as well as activities and participation. Because the impact of the syndrome profoundly influences the patient's normal life and daily activity pattern in work, home maintenance, and leisure activities (39), assessing concepts related to the component activities and participation in FM should be highlighted.

Visual analog scales for pain, fatigue, and disease activity or global health status are, per definition, self-report instruments. However, because they can be linked to a single ICF category only (b280 pain, b130 energy and drive functions) or to the health condition itself, they were not included in this analysis, which focused on a comparison of the content of instruments. Further research should focus on the psychometric properties of instruments and may suggest how to best measure specific concepts or categories. In terms of content, instruments that measure pain and fatigue not only within the ICF component body functions, but also within activities and participation may be preferable, as has been argued above.

The content of the questionnaires assessing health in patients with FM differs considerably, not the least due to the multidimensional nature of FM. Several instruments are available to assess pain, fatigue, and depression. All of them cover categories of the ICF concept body function, but not all could be linked to concepts regarding activities and participation and environmental factors. Thus, when selecting an instrument, careful consideration needs to be taken into account regarding which aspects of health should be covered. Based on the comparison made in this article, researchers and clinicians should be able to make a more informed decision about which questionnaires best cover the content of the end points they wish to assess.

\section{ACKNOWLEDGMENTS}

The authors would like to thank Edda Amann and Barbara Kollerits for linking the instruments to the ICF.

\section{AUTHOR CONTRIBUTIONS}

Ms Prodinger had full access to all of the data in the study and takes responsibility for the integrity of the data and the accuracy of the data analysis.

Study design. Prodinger, Cieza, Mease, Boonen, Stucki, Stamm. Acquisition of data. Prodinger, Cieza, Stamm.

Analysis and interpretation of data. Prodinger, Williams, Mease, Boonen, Machold, Stamm.

Manuscript preparation. Prodinger, Kerschan-Schindl, FialkaMoser, Smolen, Machold, Stamm.

Statistical analysis. Prodinger, Kerschan-Schindl, Fialka-Moser, Stamm.

\section{REFERENCES}

1. Wolfe F, Smythe HA, Yunus MB, Bennett RM, Bombardier C, Goldenberg DL, et al. The American College of Rheumatology 1990 criteria for the classification of fibromyalgia: report of the Multicenter Criteria Committee. Arthritis Rheum 1990;33: $160-72$.

2. Wolfe F, Ross K, Anderson J, Russell IJ, Hebert L. The prevalence and characteristics of fibromyalgia in the general population. Arthritis Rheum 1995;38:19-28.

3. Mease P. Fibromyalgia syndrome: review of clinical presentation, pathogenesis, outcome measures, and treatment [published erratum appears in J Rheumatol Suppl 2005;32:2063]. J Rheumatol Suppl 2005;75:6-21.

4. Blotman F, Branco J. Fibromyalgia: daily aches and pain. Toulouse (France): Editions Privat; 2007.

5. Clauw DJ, Chrousos GP. Chronic pain and fatigue syndromes: overlapping clinical and neuroendocrine features and potential pathogenic mechanisms. Neuroimmunomodulation 1997; 4:134-53.

6. Gracely RH, Petzke F, Wolf JM, Clauw DJ. Functional magnetic resonance imaging evidence of augmented pain processing in fibromyalgia. Arthritis Rheum 2002;46:1333-43.

7. Giesecke T, Williams DA, Harris RE, Cupps TR, Tian X, Tian TX, et al. Subgrouping of fibromyalgia patients on the basis of pressure-pain thresholds and psychological factors. Arthritis Rheum 2003;48:2916-22.

8. Clauw DJ, Crofford LJ. Chronic widespread pain and fibromyalgia: what we know, and what we need to know. Best Pract Res Clin Rheumatol 2003;17:685-701.

9. Turk DC, Dworkin RH. What should be the core outcomes in chronic pain clinical trials? Arthritis Res Ther 2004;6:151-4.

10. Mease P, Arnold LM, Bennett R, Boonen A, Buskila D, Carville $S$, et al. Fibromyalgia syndrome. J Rheumatol 2007;34: 1415-25.

11. World Health Organization. ICF: International Classification of Functioning, Disability and Health. Geneva: WHO; 2001.

12. Cieza A, Brockow T, Ewert T, Amman E, Kollerits B, Chatterji $S$, et al. Linking health-status measurements to the International Classification of Functioning; Disability and Health. J Rehabil Med 2002;34:205-10.

13. Cieza A, Geyh S, Chatterji S, Kostanjsek N, Ustun B, Stucki G. ICF linking rules: an update based on lessons learned. J Rehabil Med 2005;37:212-8.

14. Cohen J. A coefficient of agreement for nominal scales. Educ Psychol Meas 1960;20:46.

15. Brennan P, Silman A. Statistical methods for assessing observer variability in clinical measures. BMJ 1992;304:1491-4.

16. Stamm TA, Cieza A, Machold KP, Smolen JS, Stucki G. Con- 
tent comparison of occupation-based instruments in adult rheumatology and musculoskeletal rehabilitation based on the International Classification of Functioning, Disability and Health. Arthritis Rheum 2004;51:917-24.

17. Wolfe F, Rasker JJ. The symptom intensity scale, fibromyalgia, and the meaning of fibromyalgia-like symptoms. J Rheumatol 2006;33:2291-9.

18. Burckhardt CS, Clark SR, Bennett RM. The fibromyalgia impact questionnaire: development and validation. J Rheumatol 1991;18:728-33.

19. Melzack R. The McGill Pain Questionnaire: major properties and scoring methods. Pain 1975;1:277-99.

20. Melzack R. The short-form McGill Pain Questionnaire. Pain 1987;30:191-7.

21. Cleeland CS, Ryan KM. Pain assessment: global use of the Brief Pain Inventory. Ann Acad Med Singapore 1994;23:12938.

22. Martinez-Lavin M, Lopez S, Medina M, Nava A. Use of the Leeds assessment of neuropathic symptoms and signs questionnaire in patients with fibromyalgia. Semin Arthritis Rheum 2003;32:407-11.

23. Schneidert M, Hurst R, Miller J, Ustun B. The role of environment in the International Classification of Functioning, Disability and Health (ICF). Disabil Rehabil 2003;25:588-95.

24. Stamm TA, Nell V, Mathis M, Coenen M, Aletaha D, Cieza A, et al. Concepts important to patients with psoriatic arthritis are not adequately covered by standard measures of functioning. Arthritis Rheum 2007;57:487-94.

25. Stamm TA, Bauernfeind B, Coenen M, Feierl E, Mathis M, Stucki G, et al. Concepts important to persons with systemic lupus erythematosus and their coverage by standard measures of disease activity and health status. Arthritis Rheum 2007; 57:1287-95.

26. Rejas J, Ribera MV, Ruiz M, Masrramon X. Psychometric properties of the MOS (Medical Outcomes Study) Sleep Scale in patients with neuropathic pain. Eur J Pain 2007;11:329-40.

27. Theadom A, Cropley M, Humphrey KL. Exploring the role of sleep and coping in quality of life in fibromyalgia. J Psychosom Res 2007;62:145-51.

28. Schaefer KM. Sleep disturbances linked to fibromyalgia. Holist Nurs Pract 2003;17:120-7.
29. Affleck G, Urrows S, Tennen H, Higgins P, Abeles M. Sequential daily relations of sleep, pain intensity, and attention to pain among women with fibromyalgia. Pain 1996;68:363-8.

30. Webster K, Cella D, Yost K. The Functional Assessment of Chronic Illness Therapy (FACIT) Measurement System: properties, applications, and interpretation. Health Qual Life Outcomes 2003;1:79.

31. Krupp LB, Larocca NG, Muirnash J, Steinberg AD. The Fatigue Severity Scale: application to patients with multiple sclerosis and systemic lupus erythematosus. Arch Neurol 1989;46:1121-3.

32. Smets EM, Garssen B, Bonke B, De Haes JC. The Multidimensional Fatigue Inventory (MFI) psychometric qualities of an instrument to assess fatigue. J Psychosom Res 1995;39:31525.

33. Belza BL, Henke CJ, Yelin EH, Epstein WV, Gilliss CL. Correlates of fatigue in older adults with rheumatoid arthritis. Nurs Res 1993;42:93-9.

34. McGahuey CA, Gelenberg AJ, Laukes CA, Moreno FA, Delgado PL, McKnight KM, et al. The Arizona Sexual Experience Scale (ASEX): reliability and validity. J Sex Marital Ther 2000;26:25-40.

35. Tikiz C, Muezzinoglu T, Pirildar T, Taskin EO, Frat A, Tuzun C. Sexual dysfunction in female subjects with fibromyalgia. J Urol 2005;174:620-3.

36. McHorney CA, Ware JE Jr, Raczek AE. The MOS 36-Item Short-Form Health Survey (SF-36). II. Psychometric and clinical tests of validity in measuring physical and mental health constructs. Med Care 1993;31:247-63.

37. McHorney CA, Ware JE Jr, Lu JF, Sherbourne CD. The MOS 36-Item Short-Form Health Survey (SF-36). III. Tests of data quality, scaling assumptions, and reliability across diverse patient groups. Med Care 1994;32:40-66.

38. Faravelli C, Albanesi G, Poli E. Assessment of depression: a comparison of rating scales. J Affect Disord 1986;11:245-53.

39. Henriksson C, Burckhardt C. Impact of fibromyalgia on everyday life: a study of women in the USA and Sweden. Disabil Rehabil 1996;18:241-8.

40. Belza B. Multidimensional Assessment of Fatigue (MAF). 2007. URL: http://www.son.washington.edu/research/maf/. 